\title{
TWO LEVELS OF IRON SUPPLEMENTATION AND DEVELOPMENTAL OUTCOME, IRON NUTRITION, AND ADVERSE RESULTS IN LOW BIRTH WEIGHT INFANTS
}

\author{
J. K. Friel, P. F. Kwa, B. Simmons, K. Aziz, C. Mercer, A. MacDonald, \\ and W. L. Andrews \\ Departments of Biochemistry \& Pediatrics \\ Memorial University \\ Janeway Child Health Centre \\ St. John's, Newfoundland \\ Canada, A1B 3X9
}

Conflicting opinions exist over the optimal amount of iron that low birth weight infants (LBW $<2,500 \mathrm{~g}$ birth weight) should receive. To investigate the effect of increased dietary iron intakes we randomly assigned 58 infants at 2,000 \pm 100 gm study entry to receive either a premature formula with $12 \mathrm{mg}$ iron/L (iron) or $21 \mathrm{mg} / \mathrm{L}$ (high iron) for a period of one year. Birth weight (high iron 1,432 \pm 390 ; iron 1,491 $\pm 339 \mathrm{~g}$ ) and gestational age (high iron ( $32 \pm 2$; iron $32 \pm 3 \mathrm{wks})$ did not differ between groups. At baseline, hospital discharge, 3, 6, 9 and 12 months corrected age, the following measurements were completed: weight, infection rate; RBC hemoglobin (HGB), catalase, hydrogen peroxide fragility $\left(\mathrm{H}_{2} \mathrm{O}_{2}\right)$ and superoxide dismutase (in progress); plasma malondialdehyde (MDA), ferritin, transferrin, zinc and copper; Griffiths Mental Development Scales (GMD) and 3 day diet records. There were no differences at any time for weight, catalase, $\mathrm{MDA}, \mathrm{H}_{2} \mathrm{O}_{2}$ or GMD. HGB (High iron $123 \pm 9$; iron $118 \pm 8$ ) showed a trend at 3 months $(\mathrm{p}=0.07)$. Ferritin (High iron $17 \pm 8$; iron $12 \pm 5$ ) was greater in the high iron group at 6 months. Transferrin was greater in the high iron group at 3 months (High iron $320 \pm 32$; iron 297 \pm 43). Plasma zinc (High iron $71 \pm 13$; iron $94 \pm 26$ ) and plasma copper (High iron $107 \pm$ 24; iron $131 \pm 29 ; \mathrm{P}<0.05)$ at 12 months indicated possible inhibition of zinc and copper absorption with increased iron intake as there was no difference in zinc or copper intakes at 9 or 12 months. Infections other than respiratory, tended $(\mathrm{p}=0.01)$ to be greater in the high iron group at both 9 months $(0.06 \pm 0.05$ vs $0.03 \pm 0.05)$ and 12 months $(0.07 \pm$ 0.06 vs $0.03 \pm 0.06$ ). There appears to be no advantage to iron intakes above current recommendation for LBW infants. Supported by the Medical Research Council of Canada and Ross Laboratories. 